\title{
High bone marrow angiopoietin- I expression is an independent poor prognostic factor for survival in patients with myelodysplastic syndromes
}

\author{
C-L Cheng ',5, H-A Hou ',5, J-Y Jhuang ${ }^{2}$, C-W Lin ${ }^{2,3}$, C-Y Chen', J-L Tang', W-C Chou ${ }^{1,4}$, M-H Tseng', M Yao', \\ S-Y Huang', B-S Ko', S-C Hsu', S-J Wu', W Tsay', Y-C Chen ${ }^{1,4}$ and H-F Tien ${ }^{*, 1}$ \\ 'Division of Hematology, Department of Internal Medicine, National Taiwan University Hospital, College of Medicine, National Taiwan University, No. 7, \\ Chung-Shan South Road, Taipei 10002, Taiwan; 'Department of Pathology, National Taiwan University Hospital, College of Medicine, National Taiwan \\ University, Taipei, Taiwan; ${ }^{3}$ Tissue Bank, Center for Genomic Medicine, National Taiwan University, Taipei, Taiwan; ${ }^{4}$ Department of Laboratory Medicine, \\ National Taiwan University Hospital, College of Medicine, National Taiwan University, Taipei, Taiwan
}

BACKGROUND: Angiogenic factors have an essential role in normal and pathologic angiogenesis. However, the clinical implication of angiogenic factor expression in myelodysplastic syndromes (MDS) remains unclear.

METHODS: In this study, we sought to investigate the prognostic impact of the expression of genes encoding angiopoietin-I (Ang-I), Ang-2, the receptor Tie2, vascular endothelial growth factor-A (VEGF-A) and VEGF-C in the bone marrow (BM) in 208 patients with newly diagnosed primary MDS.

RESULTS: BM Ang-I expression was significantly higher in MDS patients, especially those with higher-risk subtypes, than in normal controls. With a median follow-up time of 32.9 months, the disease transformed to acute leukaemia more frequently in the patients bearing higher Ang-I expression than in those with lower expression (31.5\% vs 18.6\%, $P=0.023)$. The MDS patients with higher Ang-I expression had shorter overall survival than those with lower expression (median $20.8 \pm 4.5$ months vs $63.3 \pm 17.8$ months, $P<0.00$ I). Multivariate analyses showed that higher Ang-I expression was an independent unfavourable prognostic factor for overall survival. There was no impact of the expression of other angiogenic factors on survival.

CONCLUSION: BM Ang-I expression may serve as a new biomarker to predict clinical outcome in MDS patients.

British Journal of Cancer (20 I I) I 05, 975-982. doi:I0.1038/bjc.20 I I.340 www.bjcancer.com

Published online 30 August 201 I

(c) 201 I Cancer Research UK

Keywords: angiopoietin; vascular endothelial growth factor; myelodysplastic syndromes; prognosis

Angiogenesis, the sprouting of new blood vessels from an existing vasculature (Cines et al, 1998), has a crucial role in the growth, dissemination and metastasis of solid tumours (Folkman, 1971; Ellis and Fidler, 1996). Several antiangiogenic drugs have been shown to be effective in various forms of cancers, such as bevacizumab in colon cancers and lung cancers (Kabbinavar et al, 2003; Hurwitz et al, 2004; Sandler et al, 2006). Recent studies suggest that the progression of haematologic malignancies, such as acute myeloid leukaemia (AML) (Aguayo et al, 1999; Hussong et al, 2000; Padro et al, 2000), is also strongly related to angiogenesis. Myelodysplastic syndromes (MDS) are a heterogeneous group of clonal haematopoietic disorders characterised by ineffective haematopoiesis (Mufti, 2004) and a propensity to transform to AML. Growing evidences indicate a key role of angiogenesis in the pathogenesis of MDS. Bone marrow (BM) microvessel density (MVD) as displayed by immunohistochemical (IHC) staining has been shown to be higher in MDS patients than

\footnotetext{
*Correspondence: Professor H-F Tien; E-mail: hftien@ntu.edu.tw

${ }^{5}$ These authors contributed equally to this work and should be considered as joint first authors.

Received 22 February 20 I I; revised 20 July 20 I I; accepted 26 July 20 I I; published online 30 August 2011
}

in normal populations (Pruneri et al, 1999; Aguayo et al, 2000; Korkolopoulou et al, 2001; Alexandrakis et al, 2005). The studies regarding the correlation between BM MVD and the stage of MDS showed conflicting results; some reported higher MVD in high-risk MDS than in low-risk ones (Pruneri et al, 1999; Alexandrakis et al, 2005), while others did not find any difference among FrenchAmerican-British (FAB) subgroups (Lundberg et al, 2006). The prognostic implication of BM MVD in MDS patients also remains controversial (Korkolopoulou et al, 2001; Alexandrakis et al, 2005; Lundberg et al, 2006; Madry et al, 2007).

Recently, the expression of angiogenic factors including vascular endothelial growth factors (VEGF) and angiopoietin (Ang)-Tie2 receptor family was studied to evaluate the role of these factors in normal and pathologic angiogenesis. The expression of Ang and VEGF correlates well with clinical features and outcome in patients with solid cancers (Toi et al, 1994; Salven et al, 1998; Tanaka et al, 2002; Chung et al, 2006). The studies concerning clinical implication of the expression of these factors in MDS are limited. The blood levels of VEGF were increased in MDS patients compared with normal controls (Aguayo et al, 2002), especially in those with advanced MDS (Brunner et al, 2002). The mRNA expression of Ang-1, Ang-2 and the receptor Tie2 in the BM was significantly higher in MDS patients compared with normal 
controls (Keith et al, 2007). Nevertheless, the case numbers of these studies were limited. In addition, the prognostic implication of the expression of these angiogenic factors remains investigational. In this study, we investigated RNA expression of genes encoding Ang-1, Ang-2, Tie2, VEGF-A and VEGF-C by real-time quantitative polymerase chain reaction (RQ-PCR) in a cohort of 208 patients with newly diagnosed primary MDS and correlated the results with clinical features and outcome of the patients. We found that Ang-1 expression was an independent prognostic factor in MDS patients.

\section{MATERIALS AND METHODS}

\section{Patients and samples}

A total of 208 adult patients with newly diagnosed primary MDS according to FAB criteria at the National Taiwan University Hospital between January 1986 and December 2008 who had complete clinical data and available RNA for study were recruited. Twenty normal marrow donors were also enrolled for comparison. Expression of Ang-1, Ang-2, Tie2, VEGF-A and VEGF-C in the BM was determined at diagnosis. One hundred and seventy-seven (85.1\%) patients received supportive care. The remaining 31 patients were treated with AML-directed intensive chemotherapy $(n=8)$, allogeneic haematopoietic stem cell transplantation $(n=18)$ or both $(n=5)$. This study protocol was approved by the Institutional Review Board of the National Taiwan University Hospital and all patients gave their informed consent.

\section{Real-time quantitative polymerase chain reaction}

BM mononuclear cells from 208 patients and 20 healthy transplantation donors were isolated and cryopreserved until use. Total RNA was extracted, reverse transcribed and amplified by RQ-PCR as previously described (Hou et al, 2008). Each sample was tested at least twice independently. The amount of the target genes was normalised to the housekeeping gene RPLPO. The copies of target gene were quantified only after successful amplification of the internal control, using standard curves derived from cloned plasmids. All data were presented as log ratio of the target gene/ RPLPO. The sequences of primers and probes of these five angiogenic factors were listed in Supplementary Table 1.

\section{IHC staining for Ang-1 protein}

We performed IHC to assess the Ang-1 protein expression in the BM biopsy specimens from 40 selected MDS patients, 20 having higher Ang-1 mRNA expression and another 20, lower Ang-1 mRNA expression. BM biopsies were collected and placed immediately into $10 \%$ buffered formalin fixative. The fixation time was between 6 and $24 \mathrm{~h}$. The specimens were washed in tap water for 2-min and decalcified with Plank-Rychlo's solution (Muto Pure Chemicals Co., Ltd, Tokyo, Japan) in the specimen container. The decalcification time was between 90 to $120 \mathrm{~min}$. Then, we placed the specimens labelled with both surgical and BM numbers into blue cassettes and washed them with running tap water for $2 \mathrm{~h}$. Subsequently, they were placed in $10 \%$ buffered formalin until ready to load into processor. The primary antibody we used was mouse monoclonal anti-human Ang-1 (MAB923; Clone 171718; $5 \mathrm{mg} \mathrm{ml}^{-1}$; R\&D Systems, Minneapolis, MN, USA). The working concentration was $25 \mu \mathrm{g} \mathrm{ml}^{-1}$. IHC was executed as previously described (Seval et al, 2008). A score of 1-6 was calculated for each specimen according to the staining intensity ( $0=$ none, $1=$ weak, $2=$ strong) and the percentage of myeloid cells positively stained $(1=0-25 \%, 2=26-50 \%, 3=51-75 \%$, $4=76-100 \%$ ) by the pathologists who were blind to the results of Ang-1 mRNA expression. Erythroid cells were excluded from calculation.

\section{Cytogenetic study}

Chromosomal analyses were performed on BM cells after 1-3 days of unstimulated culture. The metaphase cells were banded by trypsin-Giemsa technique and karyotyped in accordance with the International System for Human Cytogenetic Nomenclature as previously described (Tien et al, 1995).

\section{Statistical analysis}

We used Mann-Whitney $U$-test to analyse the difference in the expression of Ang-1, Ang-2, Tie2, VEGF-A and VEGF-C between the MDS and control groups and between lower-risk and higherrisk MDS. Correlation between the Ang-1 mRNA expression and protein expression by IHC was accessed by the Spearman's rank correlation. Overall survival was measured from the date of first diagnosis to death from any cause or the last follow-up. We adopted Kaplan-Meier estimation to plot survival curves, and used log-rank tests to examine the difference between groups. Hazard ratio (HR) and 95\% confidence interval (CI) was estimated by Cox proportional hazards regression models to determine independent risk factors associated with overall survival in multivariate analyses. Two-sided $P$-values $<0.05$ were considered statistically significant. All statistical analyses were accomplished with the SPSS 17 (SPSS Inc., Chicago, IL, USA).

Table I The demographics of the 208 patients with myelodysplastic syndromes

\begin{tabular}{|c|c|}
\hline Variables & No. of patients (\%) \\
\hline \multicolumn{2}{|l|}{ Sex } \\
\hline Male & $143(69)$ \\
\hline Female & $65(31)$ \\
\hline Age $\left(\right.$ years) ${ }^{\mathrm{a}}$ & $65(14-88)$ \\
\hline FAB subtype & $208(100)$ \\
\hline RA & $77(37)$ \\
\hline RARS & $13(6.3)$ \\
\hline RAEB & 81 (38.9) \\
\hline RAEB-t & $19(9.1)$ \\
\hline CMML & $18(8.7)$ \\
\hline WHO classification & |7| (100) \\
\hline RCUD & $36(2 \mathrm{I})$ \\
\hline RARS & $10(5.8)$ \\
\hline RCMD & $41(24)$ \\
\hline RAEB-I or 2 & $81(47.4)$ \\
\hline MDS-U & $3(1.8)$ \\
\hline Karyotype & $196(100)$ \\
\hline Good & $125(63.8)$ \\
\hline Intermediate & $36(18.4)$ \\
\hline Poor & $35(17.8)$ \\
\hline IPSS $^{C}$ & $196(100)$ \\
\hline Low & $27(13.8)$ \\
\hline INT-I & $93(47.4)$ \\
\hline INT-2 & $54(27.6)$ \\
\hline High & $22(11.2)$ \\
\hline
\end{tabular}

Abbreviations: $\quad F A B=$ French - American - British classification; $\quad R A=$ refractory anaemia; $R A R S=$ refractory anaemia with ring sideroblasts; RAEB = refractory anaemia with excess blasts; RAEB-t = refractory anaemia with excess blasts in transformation; $\mathrm{CMML}=$ chronic myelomonocytic leukaemia; $\mathrm{RCUD}=$ refractory cytopenia with unilineage dysplasia; RCMD = refractory cytopenia with multilineage dysplasia; MDS- $U$ = myelodysplastic syndrome-unclassified; IPSS = international prog-

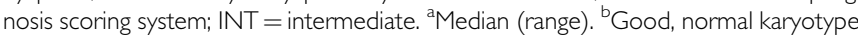
isolated $-Y$, del $(5 q)$ or del(20q); poor, complex ( $\geqslant 3$ abnormalities) or chromosome 7 anomalies; Intermediate, other abnormalities. International prognosis scoring system: low, 0; intermediate (INT)- I, 0.5-I; INT-2, I.5-2; and high, ₹2.5. The 196 patients with chromosome data could be stratified by this scoring system. 


\section{RESULTS}

\section{Characteristics of the patients}

Among the 208 MDS patients recruited (Table 1), 143 were males and 65 were females with a median age of 65 years (range, 14-88). According to the FAB classification $(n=208), 77$ patients had refractory anaemia (RA), 13 RA with ring sideroblasts (RARS), 81 RA with excess blasts (RAEB), 19 RAEB in transformation (RAEB-t) and 18 chronic myelomonocytic leukaemia. Compared with MDS patients in the United States (Rollison et al, 2008), our cohort had higher incidence of RAEB/RAEB-t $(48.1 \%$ vs $15.5 \%, P<0.0001)$ but lower incidence of RARS $(6.25 \%$ vs $11.6 \%, P=0.0147)$, similar to those in Korea, an Asian country (Lee et al, 2003). By the World Health Organization (WHO)-2008 classification $(n=171)$, 36 patients had refractory cytopenia with unilineage dysplasia; 10 RARS; 41 refractory cytopenia with multilineage dysplasia; 81 RAEB-1 or RAEB-2; and three, MDS-unclassified.

One hundred and ninety-six patients had cytogenetic data, thus could be stratified by international prognosis scoring system (IPSS); 27 patients were in low, 93 in intermediate-1 (INT-1), 54 in INT-2 and 22 in high-risk groups.

\section{Comparison of angiogenic factor expression between MDS patients and normal controls}

The expression of Ang-1, Ang-2, Tie2, VEGF-A and VEGF-C was quantified as a ratio with the expression of the housekeeping gene $R P L P 0$. We found that the median levels of Ang-1, Tie2, VEGF-A and $V E G F-C$ were significantly higher $(P$-value all $<0.001$; Supplementary Figure 1), but that of Ang-2 was significantly lower $(P=0.019)$ in MDS patients than in normal controls.

\section{Correlation between Ang-1 RNA expression and protein expression}

Ang-1 protein expression measured by scoring of IHC correlated well with mRNA expression in the 40 patients studied $(P=0.0057$ by Spearman's rank correlation). Representative IHC of a sample with a higher score and another one with a lower score were demonstrated in Figure 1. Further, in order to directly demonstrate that BM blasts of MDS patients actually express Ang-1 protein, we prospectively sorted $\mathrm{CD}_{3}{ }^{+}$cells from BM mononuclear cells by fluorescence activated cell sorter (FACSAria; BD Bioscience, San Jose, CA, USA) in two patients diagnosed as having RA with excess blasts and then performed immunocytochemical staining of these sorted $\mathrm{CD} 34^{+}$cells by immunoperoxidase technique. We showed that Ang-1 was strongly stained in these $\mathrm{CD}_{3}{ }^{+}$cells (Supplementary Figure 2). It provided evidences that BM blasts might contribute to the Ang-1 protein expression in MDS patients.

\section{Association between BM angiogenic factor expressions and clinical features}

Correlations between the expression of angiogenic factors and sex, age, hemogram, and FAB, WHO and IPSS subtypes were assessed. The Ang-1 expression was much higher in FAB RAEB or RAEB-t subgroup than in RA or RARS subgroup; in WHO RAEB-1 or RAEB-2 subgroup than in other categories; and in IPSS INT-2/ high-risk subgroup than in low/INT-1 subgroup (all $P$-value $<0.001$; Supplementary Figure 3). Furthermore, the Ang-2 expression was also higher in INT-2/high than in low/INT-1 subgroup $(P=0.03)$ but was not different among FAB or WHO subtypes (Supplementary Table 2). On the contrary, the VEGF-A expression was higher in FAB RA or RARS subgroup than in RAEB or RAEB-t subgroup $(P=0.017)$ but was not different among WHO or IPSS subtypes. The expressions of Tie2 and VEGF-C were similar between higher-risk and lower-risk subtypes by FAB, WHO or IPSS classification. There was no correlation between the expression of any one of the five angiogenic factors and sex and age. Regarding the hemogram, patients with normal platelet count $\left(\geqslant 10^{5}\right.$ per $\left.\mu \mathrm{l}\right)$ had higher VEGF-C expression $(P<0.001)$, and those with normal absolute neutrophil count $(\geqslant 1800$ per $\mu \mathrm{l})$ had higher VEGF-A expression $(P=0.029)$ (Supplementary Table 2).
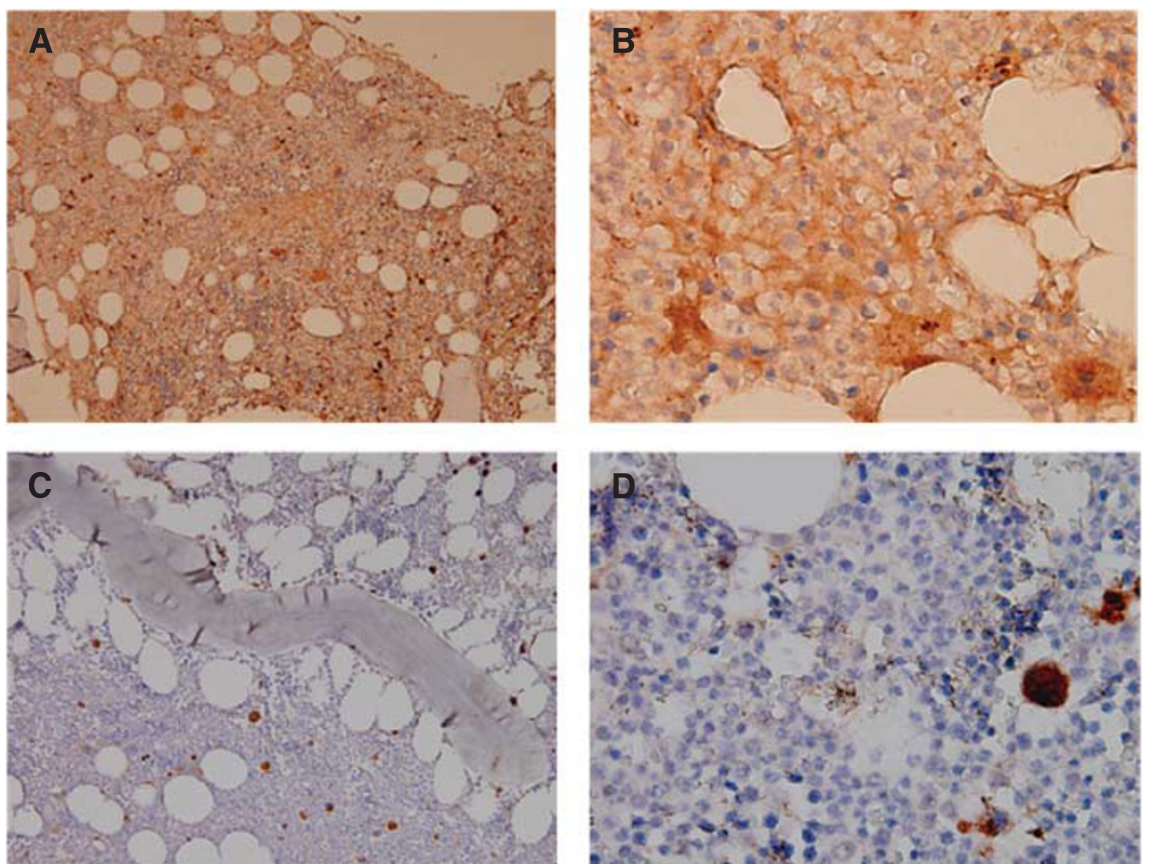

Figure I Representative IHC stainings of Ang-I protein in BM biopsy specimens from two patients showing strong staining in one specimen from a patient with higher Ang-I mRNA expression (A and B), while weak staining in another specimen from a patient with lower mRNA expression (C and $\mathbf{D})$. Megakaryocytes were served as positive internal control (magnification $\times 200$ and $\times 1000$, respectively). 
Table 2 Univariate analysis of the impact of angiogenic factor on overall survival in MDS patients

\begin{tabular}{|c|c|c|c|}
\hline Variable & No. of patients & Overall survival $^{\mathrm{a}}$ & $P$-value \\
\hline Sex & & & 0.378 \\
\hline Male & 143 & $28.7 \pm 5.5$ & \\
\hline Female & 65 & $62.2 \pm 20.2$ & \\
\hline Age (years) & & & 0.029 \\
\hline$<60$ & 83 & $68.9 \pm 23.4$ & \\
\hline$\geqslant 60$ & 125 & $27.9 \pm 4.1$ & \\
\hline Karyotype & & & $<0.001$ \\
\hline Good/intermediate & 161 & $39.2 \pm 11.1$ & \\
\hline Poor & 35 & $9.5 \pm 2.2$ & \\
\hline FAB classification & & & $<0.001$ \\
\hline RA/RARS & 90 & $68.9 \pm 10.3$ & \\
\hline RAEB & 81 & $18.3 \pm 2.4$ & \\
\hline RAEB-t & 19 & $14.8 \pm 3.2$ & \\
\hline IPSS & & & $<0.001$ \\
\hline Low/INT-I & 120 & $62.2 \pm 5.5$ & \\
\hline INT-2/high & 76 & $14.3 \pm 2.4$ & \\
\hline Ang-I & & & $<0.001$ \\
\hline Low & 104 & $63.3 \pm 17.8$ & \\
\hline High & 104 & $20.8 \pm 4.5$ & \\
\hline Ang-2 & & & 0.151 \\
\hline Low & 104 & $32 \pm 14.4$ & \\
\hline High & 104 & $29.3 \pm 4.1$ & \\
\hline Tie2 & & & 0.344 \\
\hline Low & 104 & $29.3 \pm 14.5$ & \\
\hline High & 104 & $30.4 \pm 5.4$ & \\
\hline VEGF-A & & & 0.860 \\
\hline Low & 104 & $29.3 \pm 5.5$ & \\
\hline High & 104 & $32 \pm 12.1$ & \\
\hline VEGF-C & & & 0.921 \\
\hline Low & 104 & $28.7 \pm 8$ & \\
\hline High & 104 & $32 \pm 13.8$ & \\
\hline
\end{tabular}

Abbreviations: $\mathrm{MDS}=$ myelodysplastic syndromes; $\mathrm{FAB}=$ French - American - British classification; $R A=$ refractory anaemia; $R A R S=$ refractory anaemia with ring sideroblasts; $\mathrm{RAEB}=$ refractory anaemia with excess blasts; $\mathrm{RAEB}-\mathrm{t}=$ refractory anaemia with excess blasts in transformation; IPSS = international prognosis scoring system INT = intermediate; Ang = angiopoietin; VEGF = vascular endothelial growth factor. a Median (months \pm s.d.). Median value of each angiogenic factor was used as the cutoff level to define low- and high-expression groups.

\section{Association between BM angiogenic factor expressions and overall survival}

The median value of each angiogenic factor expression was used as the cutoff level to divide patients into low- and high-expression groups. With a median follow-up time of 32.9 months (range, $0.03-196)$, the patients bearing higher Ang-1 expression had higher frequency of disease transformation to acute leukaemia compared with those bearing lower Ang-1 expression (31.5\% vs $18.6 \%, P=0.023)$. Moreover, the patients with higher Ang-1 expression had shorter overall survival than those with lower expression (median 20.8 \pm 4.5 months vs $63.3 \pm 17.8$ months, $P<0.001$; Table 2; Figure 2). Similar result could be demonstrated in the 171 patients diagnosed according to WHO classification (median 21.3 \pm 3.8 months vs $68.9 \pm 27.3$ months, $P<0.001$; Figure 2). The comparison of demographics between patients with lower and higher Ang-1 expression was listed in Supplementary
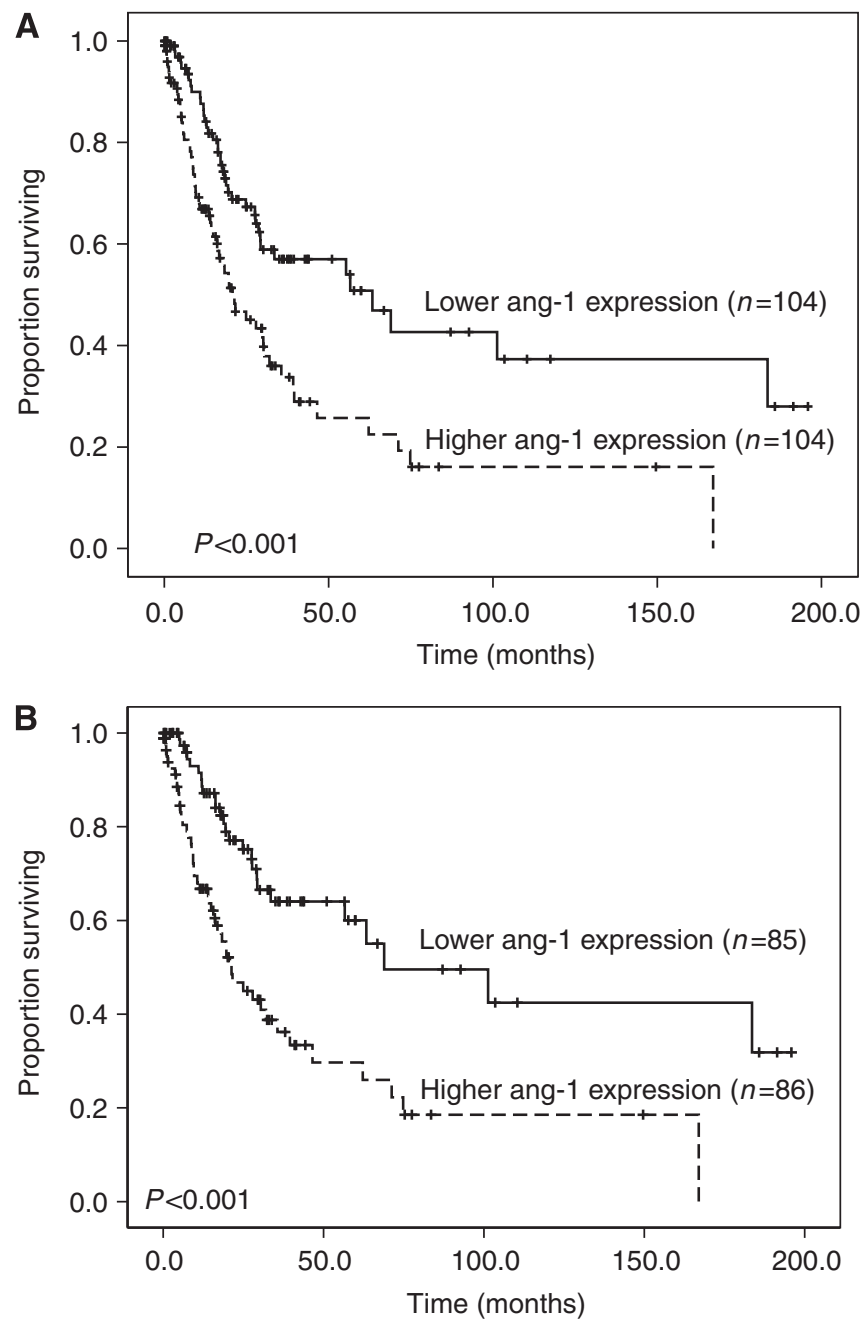

Figure 2 Kaplan-Meier curves of overall survival in all patients with newly diagnosed MDS according to $(\mathbf{A}) \mathrm{FAB}$ and $(\mathbf{B})$ WHO classifications stratified by the level of Ang-I expression (both log-rank test, $P<0.00$ I).

Table 3. Poor-risk cytogenetics occurred more frequently in the patients with higher $A n g-1$ expression than in those with lower expression (24 out of 99 or $24.2 \%$ vs 11 out of 97 or $11.3 \%$, $P=0.025)$. There was no difference in other variables including sex, age, hemogram and treatment between the two groups. The expression of $A n g-2$, Tie2, VEGF-A and $V E G F-C$ did not influence the clinical outcome (Table 2; Figure 3).

Variables including age, sex, karyotype, IPSS score and Ang-1 expression were enrolled for the Cox proportional hazards multivariate analysis. The result distinctly identified higher Ang-1 expression as an independent unfavourable prognostic factor for overall survival ( $\mathrm{HR}=1.866 ; 95 \% \mathrm{CI}, 1.204-2.892, P=0.005)$; along with other poor-risk factors, including higher IPSS score (INT-2 and high-risk subgroups) (HR $=2.808, \quad 95 \%$ CI, 1.796-4.389, $P<0.001)$, poor-risk karyotype $(\mathrm{HR}=2.031$, $95 \% \mathrm{CI}, 1.221-3.377, P=0.006)$ and age $\geqslant 60$ years $(\mathrm{HR}=2.02$, $95 \%$ CI, $1.266-3.222, P=0.003$ ) (Table 3 ).

\section{DISCUSSION}

The present study showed that higher Ang-1 expression in the BM is an independent poor prognostic factor for overall survival in MDS patients irrespective of age, karyotype and IPSS score. 

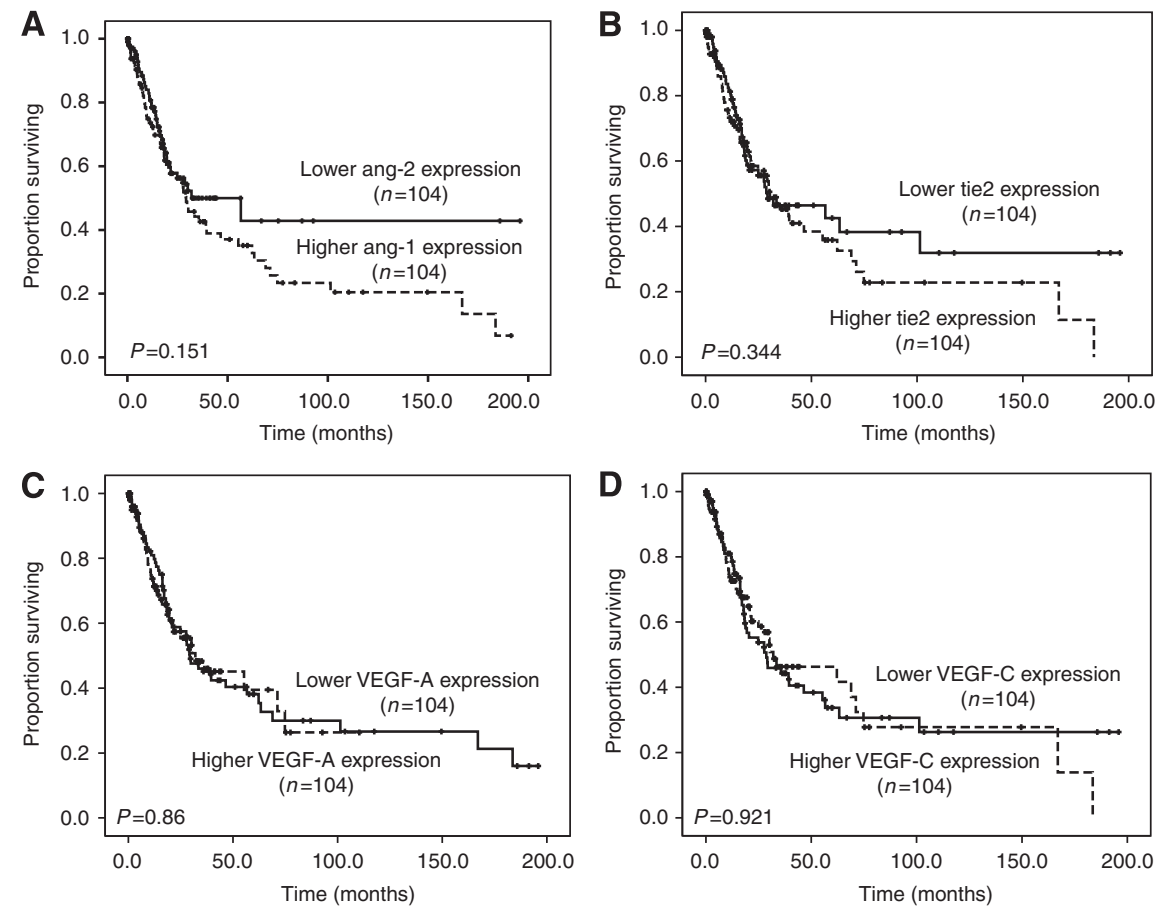

Figure 3 Kaplan-Meier curves of overall survival in all patients with newly diagnosed MDS stratified by the expression of $(\mathbf{A})$ Ang-2, (B) Tie2, (C) VEGF-A and (D) VEGF-C, respectively. None had impact on prognosis.

Table 3 Multivariate analysis (Cox regression) of sex, age, karyotype, IPSS and Ang-I expression on the overall survival in MDS patients

\begin{tabular}{lccr}
\hline Variable & Hazard ratio & $\mathbf{9 5 \%} \mathbf{C l}$ & $\boldsymbol{P}$-value \\
\hline Sex $^{\mathrm{a}}$ & 1.137 & $0.719-1.799$ & 0.582 \\
Age $^{\mathrm{b}}$ & 2.02 & $1.266-3.222$ & 0.003 \\
Karyotype $^{\mathrm{c}}$ & 2.031 & $1.221-3.377$ & 0.006 \\
IPSS $^{\mathrm{d}}$ & 2.808 & $1.796-4.389$ & $<0.001$ \\
Ang- $^{\mathrm{e}}$ & 1.866 & $1.204-2.892$ & 0.005 \\
\hline
\end{tabular}

Abbreviations: IPSS = international prognosis scoring system; Ang- I = angiopoietin- I; $\mathrm{MDS}=$ myelodysplastic syndromes; $\mathrm{Cl}=$ confidence interval. ${ }^{\mathrm{a}}$ Male vs female. ${ }^{\mathrm{b}}$ Age $\geqslant 60$ years old vs age $<60$ years old. 'Poor karyotype vs good and intermediate karyotypes. Intermediate-2/high risk vs low risk/intermediate-I. Higher Ang-I expression vs lower Ang-I expression.

Additionally, patients having higher Ang-1 expression would have higher chance of disease transformation to AML. To the best of our knowledge, this is the first report to demonstrate the prognostic implication of the Ang in MDS.

Relying on the work of the pioneer, Judah Folkman, and several successors, angiogenesis is proved to be fundamental to tumour growth and metastasis, including solid cancers and haematological malignancies (Folkman, 1971; Ellis and Fidler, 1996; Carmeliet and Jain, 2000; Hanahan and Weinberg, 2000; Hussong et al, 2000; Padro et al, 2000; Shih et al, 2009; Hou et al, 2010). MDS are considered to result from genetic and epigenetic aberrations, but the BM microenvironments including angiogenesis may also have a role (Aguayo et al, 2000; Tefferi and Vardiman, 2009). However, the clinical implication of angiogenesis in MDS remains unclear. Previous studies showed conflicting findings regarding the relationship of angiogenesis to clinical outcome in MDS patients. In one report, lower BM MVD was associated with significantly longer survival in univariate analysis, but it was not an independent prognostic factor by multivariate Cox regression analysis (Alexandrakis et al, 2005). In another study, decreased
MVD was an independent predictor of longer progression-free survival, but not overall survival (Korkolopoulou et al, 2001), while in other studies, no prognostic role of MVD could be demonstrated (Lundberg et al, 2006; Madry et al, 2007).

Although the expression of VEGF family and the Ang/Tie2 receptor family correlates with clinical features and outcome in several solid cancers and haematological malignancies (Toi et al, 1994; O'Brien et al, 1995; Takahashi et al, 1995; Salven et al, 1998; Aguayo et al, 1999, 2002; Etoh et al, 2001; Tanaka et al, 2002; Sfiligoi et al, 2003; Chung et al, 2006), little is known about the prognostic implication of the expression of these angiogenic factors in MDS. It was reported that higher protein levels of VEGF in the BM were associated with shorter survival in MDS patients (Verstovsek et al, 2002). But only 41 MDS patients were recruited in that study. No prognostic significance of plasma VEGF levels in MDS patients was demonstrated in another report (Aguayo et al, 2002). Though Keith et al (2007) reported that the mRNA expression of Ang-1, Ang-2 and the receptor Tie2 in the BM was significantly higher in MDS patients, they did not show the data regarding prognosis. In this study, a large cohort of MDS patients was recruited to correlate the mRNA expression of five angiogenic factors including $V E G F-A, V E G F-C, A n g-1, A n g-2$ and the receptor Tie 2 in the BM with the clinical outcome. The result exhibited that Ang-1, Tie2, VEGF-A and VEGF-C expression were higher, but Ang-2 expression was lower in the BM of MDS patients compared with normal controls. The expression of Ang-1 was consistently more elevated in higher-risk than in lower-risk subtypes of MDS by all three classification systems (Supplementary Table 2). In addition, higher expression of Ang-1 was an independent unfavourable prognostic factor for overall survival by multivariate analysis, and was associated with a higher chance of transformation to AML.

Like the VEGF family, the Ang/Tie2 signalling system is necessary for angiogenesis. The Ang family consists of Ang-1, 2, 3 and 4 . They are extracellular ligands that specifically bind to a receptor tyrosine kinase, Tie 2 on the surface of endothelial cells (Tait and Jones, 2004). Ang-1/Tie2 signalling cascade promotes the 

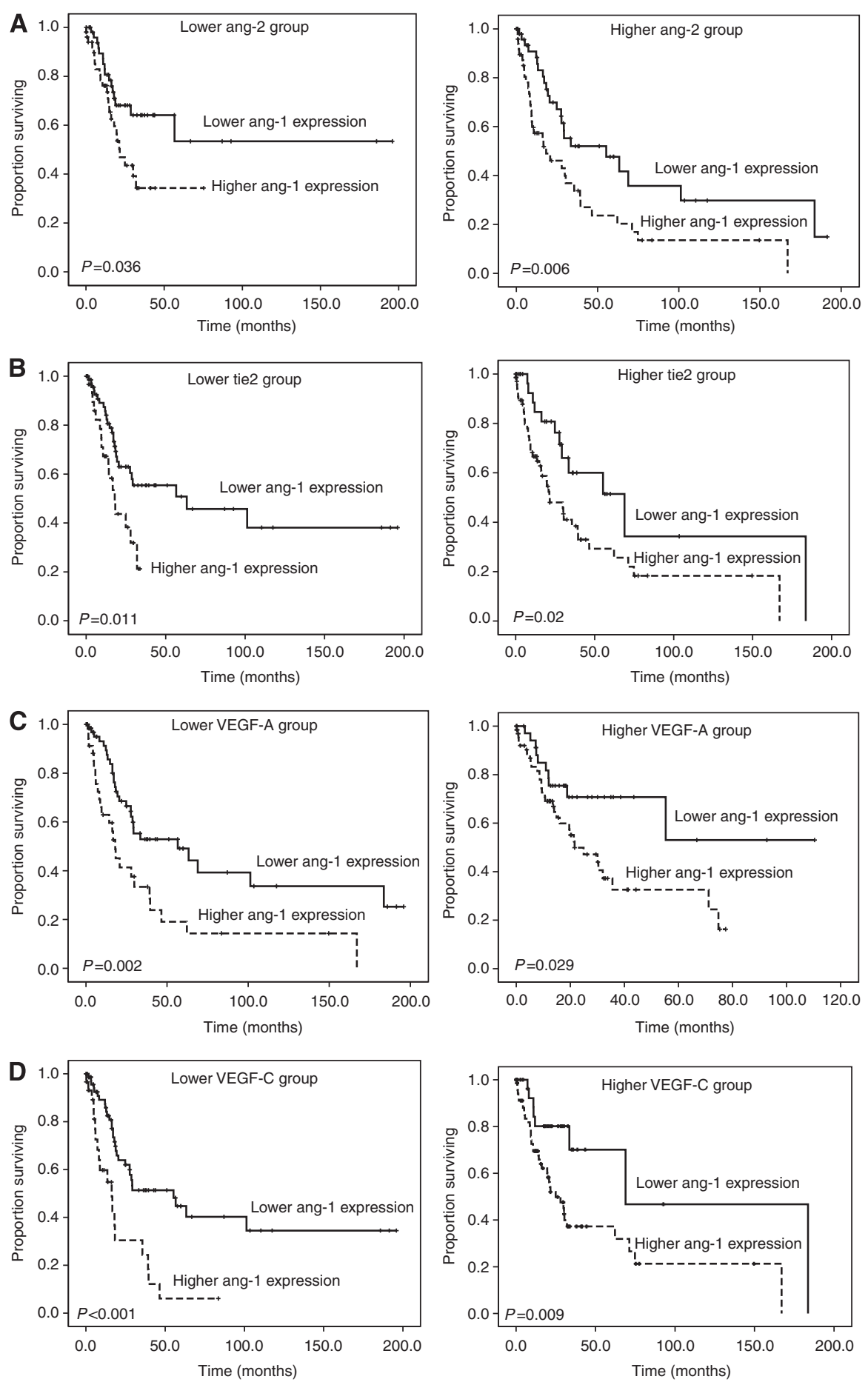

Figure 4 Subgroup analysis: Kaplan-Meier curves of overall survival stratified by Ang-I expression in the cohorts with low or high expression of (A) Ang-2, (B) Tie2, (C) VEGF-A and (D) VEGF-C. The significance of Ang-I expression for overall survival was not influenced by the levels of other angiogenic factors,

association of endothelium and pericytes (Armulik et al, 2005) and stimulates angiogenesis (Suri et al, 1998). Ang-1 regulates endothelial cell survival and maintains the integrity of vasculatures by autophosphorylation of Tie2 (Kim et al, 2000). Ang-2 does not result in activation of the receptor Tie2. It acts as a natural competitive inhibitor of Ang-1 (Maisonpierre et al, 1997). Without the presence of VEGF-A or other mitogenic factors, Ang-2 conveys a signal of vessel destabilisation, apoptosis and regression. In coordination with VEGF-A, however, it promotes proliferation and migration of endothelial cell, thereby inducing angiogenesis (Stratmann et al, 1998; Holash et al, 1999; Lobov et al, 2002). Thus, both Ang-1 and Ang-2 have pivotal, but different functions in the regulation of angiogenesis depending on the quantitative balance between these factors and other angiogenic factors. We previously demonstrated that higher expression of Ang-2, but not $A n g-1$, in the BM was a poor prognostic factor for overall survival in AML, particularly in the subgroup with high VEGF-A or VEGF-C levels (Hou et al, 2008). However, in this study, higher expression 
of Ang-1, but not Ang-2, predicted a poor outcome in MDS patients, no matter the levels of other angiogenic factors were high or low (Figure 4). The reason why the angiogenic factor that can predict the overall survival is different between MDS and AML is unclear. We and others showed Ang-1, Ang-2 and VEGF-A expression levels were all increased in AML (de Bont et al, 2001; Watarai et al, 2002; Hou et al, 2008). However, in contrast to Ang-1 and VEGF-A, which also showed higher expression in MDS patients than in normal controls, Ang-2 expression was decreased in MDS patients (Supplementary Figure 1). Since coexpression of Ang-1 and VEGF-A enhances angiogenesis (Millauer et al, 1993; Suri et al, 1998; Ferrara et al, 2003), Ang-1 may have a more important role than Ang-2 in the pathogenesis of MDS.

There are some limitations in our study. First, BM biopsies were not done in all patients; hence, Ang-1 protein expression could not be measured by scoring of IHC in every case. However, we distinctly showed that there was a significant correlation between Ang-1 protein and mRNA expression in the 40 selected MDS patients. Second, the correlation between the expression of angiogenic factors and MVD were not done either. Recently, a dynamic contrast enhanced-magnetic resonance imaging (DCEMRI) technique was developed to measure blood flow and perfusion in the BM of AML patients (Shih et al, 2009; Hou et al, 2010). Increased BM angiogenesis shown by this functional image foretold adverse outcome of AML patients. Further study to correlate the data of MVD, expression of angiogenic factors and DCE-MRI in the BM of MDS patients is warranted to have a better overview of the prognostic implication of angiogenesis in MDS.

To sum up, our study demonstrated that the expression of Ang-1 was much more elevated in higher-risk than in lower-risk subtypes of MDS and was positively associated with disease transformation to acute leukaemia. The BM Ang-1 expression was an independent prognostic factor for overall survival in MDS patients. It may serve as a new biomarker for foreseeing the clinical outcome and to stratify MDS patients for risk-adapted treatment. Inhibition of Ang-1 expression may represent a therapeutic approach for patients with higher expression of this angiogenic factor.

\section{ACKNOWLEDGEMENTS}

This work was partially sponsored by Grants NSC 97-2314-B002015-MY3 and NSC-97-2628-B-002-002-MY3 from the National Science Council (Taiwan), DOH99-TD-C-111-001 from the Department of Health (Taiwan) and NTUH.99P14 from the Department of Medical Research, National Taiwan University Hospital.

Supplementary Information accompanies the paper on British Journal of Cancer website (http://www.nature.com/bjc)

\section{REFERENCES}

Aguayo A, Estey E, Kantarjian H, Mansouri T, Gidel C, Keating M, Giles F, Estrov Z, Barlogie B, Albitar M (1999) Cellular vascular endothelial growth factor is a predictor of outcome in patients with acute myeloid leukemia. Blood 94(11): 3717-3721

Aguayo A, Kantarjian H, Manshouri T, Gidel C, Estey E, Thomas D, Koller C, Estrov Z, O'Brien S, Keating M, Freireich E, Albitar M (2000) Angiogenesis in acute and chronic leukemias and myelodysplastic syndromes. Blood 96(6): 2240-2245

Aguayo A, Kantarjian HM, Estey EH, Giles FJ, Verstovsek S, Manshouri T, Gidel C, O'Brien S, Keating MJ, Albitar M (2002) Plasma vascular endothelial growth factor levels have prognostic significance in patients with acute myeloid leukemia but not in patients with myelodysplastic syndromes. Cancer 95(9): $1923-1930$

Alexandrakis MG, Passam FH, Pappa CA, Sfiridaki K, Tsirakis G, Damilakis J, Stathopoulos EN, Kyriakou DS (2005) Relation between bone marrow angiogenesis and serum levels of angiogenin in patients with myelodysplastic syndromes. Leuk Res 29(1): 41-46

Armulik A, Abramsson A, Betsholtz C (2005) Endothelial/pericyte interactions. Circ Res 97(6): 512-523

Brunner B, Gunsilius E, Schumacher P, Zwierzina H, Gastl G, Stauder R (2002) Blood levels of angiogenin and vascular endothelial growth factor are elevated in myelodysplastic syndromes and in acute myeloid leukemia. J Hematother Stem Cell Res 11(1): 119-125

Carmeliet P, Jain RK (2000) Angiogenesis in cancer and other diseases. Nature 407(6801): 249-257

Chung YC, Hou YC, Chang CN, Hseu TH (2006) Expression and prognostic significance of angiopoietin in colorectal carcinoma. J Surg Oncol 94(7): $631-638$

Cines DB, Pollak ES, Buck CA, Loscalzo J, Zimmerman GA, McEver RP, Pober JS, Wick TM, Konkle BA, Schwartz BS, Barnathan ES, McCrae KR, Hug BA, Schmidt AM, Stern DM (1998) Endothelial cells in physiology and in the pathophysiology of vascular disorders. Blood 91(10): 3527-3561

de Bont ES, Rosati S, Jacobs S, Kamps WA, Vellenga E (2001) Increased bone marrow vascularization in patients with acute myeloid leukaemia: a possible role for vascular endothelial growth factor. Br J Haematol 113(2): $296-304$

Ellis LM, Fidler IJ (1996) Angiogenesis and metastasis. Eur J Cancer 32A(14): $2451-2460$

Etoh T, Inoue H, Tanaka S, Barnard GF, Kitano S, Mori M (2001) Angiopoietin-2 is related to tumor angiogenesis in gastric carcinoma: possible in vivo regulation via induction of proteases. Cancer Res 61(5): $2145-2153$
Ferrara N, Gerber HP, LeCouter J (2003) The biology of VEGF and its receptors. Nat Med 9(6): 669-676

Folkman J (1971) Tumor angiogenesis: therapeutic implications. N Engl J Med 285(21): $1182-1186$

Hanahan D, Weinberg RA (2000) The hallmarks of cancer. Cell 100(1): $57-70$

Holash J, Maisonpierre PC, Compton D, Boland P, Alexander CR, Zagzag D, Yancopoulos GD, Wiegand SJ (1999) Vessel cooption, regression, and growth in tumors mediated by angiopoietins and VEGF. Science 284(5422): $1994-1998$

Hou HA, Chou WC, Lin LI, Tang JL, Tseng MH, Huang CF, Yao M, Chen CY, Tsay W, Tien HF (2008) Expression of angiopoietins and vascular endothelial growth factors and their clinical significance in acute myeloid leukemia. Leuk Res 32(6): 904-912

Hou HA, Shih TT, Liu CY, Chen BB, Tang JL, Yao M, Huang SY, Chou WC, Hsu CY, Tien HF (2010) Changes in magnetic resonance bone marrow angiogenesis on day 7 after induction chemotherapy can predict outcome of acute myeloid leukemia. Haematologica 95(8): 1420-1424

Hurwitz H, Fehrenbacher L, Novotny W, Cartwright T, Hainsworth J, Heim W, Berlin J, Baron A, Griffing S, Holmgren E, Ferrara N, Fyfe G, Rogers B, Ross R, Kabbinavar F (2004) Bevacizumab plus irinotecan, fluorouracil, and leucovorin for metastatic colorectal cancer. $N$ Engl J Med 350(23): $2335-2342$

Hussong JW, Rodgers GM, Shami PJ (2000) Evidence of increased angiogenesis in patients with acute myeloid leukemia. Blood 95(1): $309-313$

Kabbinavar F, Hurwitz HI, Fehrenbacher L, Meropol NJ, Novotny WF, Lieberman G, Griffing S, Bergsland E (2003) Phase II, randomized trial comparing bevacizumab plus fluorouracil (FU)/leucovorin (LV) with FU/ $\mathrm{LV}$ alone in patients with metastatic colorectal cancer. J Clin Oncol 21(1): $60-65$

Keith T, Araki Y, Ohyagi M, Hasegawa M, Yamamoto K, Kurata M, Nakagawa Y, Suzuki K, Kitagawa M (2007) Regulation of angiogenesis in the bone marrow of myelodysplastic syndromes transforming to overt leukaemia. Br J Haematol 137(3): 206-215

Kim I, Kim HG, So JN, Kim JH, Kwak HJ, Koh GY (2000) Angiopoietin-1 regulates endothelial cell survival through the phosphatidylinositol 3'-Kinase/Akt signal transduction pathway. Circ Res 86(1): 24-29

Korkolopoulou P, Apostolidou E, Pavlopoulos PM, Kavantzas N, Vyniou N, Thymara I, Terpos E, Patsouris E, Yataganas X, Davaris P (2001) Prognostic evaluation of the microvascular network in myelodysplastic syndromes. Leukemia 15(9): 1369-1376 
Lee JH, Shin YR, Lee JS, Kim WK, Chi HS, Park CJ, Seo EJ, Lee KH (2003) Application of different prognostic scoring systems and comparison of the FAB and WHO classifications in Korean patients with myelodysplastic syndrome. Leukemia 17(2): 305-313

Lobov IB, Brooks PC, Lang RA (2002) Angiopoietin-2 displays VEGFdependent modulation of capillary structure and endothelial cell survival in vivo. Proc Natl Acad Sci USA 99(17): 11205-11210

Lundberg LG, Hellstrom-Lindberg E, Kanter-Lewensohn L, Lerner R, Palmblad J (2006) Angiogenesis in relation to clinical stage, apoptosis and prognostic score in myelodysplastic syndromes. Leuk Res 30(3): $247-253$

Madry K, Dwilewicz-Trojaczek J, Suleiman W, Paszkowska-Kowalewska M, Ziarkiewicz-Wroblewska B (2007) Angiogenesis in bone marrow of myelodysplastic syndrome patients. Pol Arch Med Wewn 117(4): 25-30

Maisonpierre PC, Suri C, Jones PF, Bartunkova S, Wiegand SJ, Radziejewski C, Compton D, McClain J, Aldrich TH, Papadopoulos N, Daly TJ, Davis S, Sato TN, Yancopoulos GD (1997) Angiopoietin-2, a natural antagonist for Tie2 that disrupts in vivo angiogenesis. Science 277(5322): $55-60$

Millauer B, Wizigmann-Voos S, Schnurch H, Martinez R, Moller NP, Risau W, Ullrich A (1993) High affinity VEGF binding and developmental expression suggest Flk-1 as a major regulator of vasculogenesis and angiogenesis. Cell 72(6): $835-846$

Mufti GJ (2004) Pathobiology, classification, and diagnosis of myelodysplastic syndrome. Best Pract Res Clin Haematol 17(4): 543-557

O’Brien T, Cranston D, Fuggle S, Bicknell R, Harris AL (1995) Different angiogenic pathways characterize superficial and invasive bladder cancer. Cancer Res 55(3): 510-513

Padro T, Ruiz S, Bieker R, Burger H, Steins M, Kienast J, Buchner T, Berdel WE, Mesters RM (2000) Increased angiogenesis in the bone marrow of patients with acute myeloid leukemia. Blood 95(8): 2637-2644

Pruneri G, Bertolini F, Soligo D, Carboni N, Cortelezzi A, Ferrucci PF, Buffa R, Lambertenghi-Deliliers G, Pezzella F (1999) Angiogenesis in myelodysplastic syndromes. Br J Cancer 81(8): 1398-1401

Rollison DE, Howlader N, Smith MT, Strom SS, Merritt WD, Ries LA, Edwards BK, List AF (2008) Epidemiology of myelodysplastic syndromes and chronic myeloproliferative disorders in the United States, 2001-2004, using data from the NAACCR and SEER programs. Blood 112(1): $45-52$

Salven P, Ruotsalainen T, Mattson K, Joensuu H (1998) High pre-treatment serum level of vascular endothelial growth factor (VEGF) is associated with poor outcome in small-cell lung cancer. Int $J$ Cancer 79(2): $144-146$

Sandler A, Gray R, Perry MC, Brahmer J, Schiller JH, Dowlati A, Lilenbaum R, Johnson DH (2006) Paclitaxel-carboplatin alone or with bevacizumab for non-small-cell lung cancer. $N$ Engl J Med 355(24): 2542-2550
Seval Y, Sati L, Celik-Ozenci C, Taskin O, Demir R (2008) The distribution of angiopoietin-1, angiopoietin-2 and their receptors tie-1 and tie-2 in the very early human placenta. Placenta 29(9): 809-815

Sfiligoi C, de Luca A, Cascone I, Sorbello V, Fuso L, Ponzone R, Biglia N, Audero E, Arisio R, Bussolino F, Sismondi P, De Bortoli M (2003) Angiopoietin-2 expression in breast cancer correlates with lymph node invasion and short survival. Int J Cancer 103(4): 466-474

Shih TT, Hou HA, Liu CY, Chen BB, Tang JL, Chen HY, Wei SY, Yao M, Huang SY, Chou WC, Hsu SC, Tsay W, Yu CW, Hsu CY, Tien HF, Yang PC (2009) Bone marrow angiogenesis magnetic resonance imaging in patients with acute myeloid leukemia: peak enhancement ratio is an independent predictor for overall survival. Blood 113(14): $3161-3167$

Stratmann A, Risau W, Plate KH (1998) Cell type-specific expression of angiopoietin-1 and angiopoietin-2 suggests a role in glioblastoma angiogenesis. Am J Pathol 153(5): 1459-1466

Suri C, McClain J, Thurston G, McDonald DM, Zhou H, Oldmixon EH, Sato TN, Yancopoulos GD (1998) Increased vascularization in mice overexpressing angiopoietin-1. Science 282(5388): 468-471

Tait CR, Jones PF (2004) Angiopoietins in tumours: the angiogenic switch. J Pathol 204(1): $1-10$

Takahashi Y, Kitadai Y, Bucana CD, Cleary KR, Ellis LM (1995) Expression of vascular endothelial growth factor and its receptor, KDR, correlates with vascularity, metastasis, and proliferation of human colon cancer. Cancer Res 55(18): 3964-3968

Tanaka F, Ishikawa S, Yanagihara K, Miyahara R, Kawano Y, Li M, Otake Y, Wada H (2002) Expression of angiopoietins and its clinical significance in non-small cell lung cancer. Cancer Res 62(23): 7124-7129

Tefferi A, Vardiman JW (2009) Myelodysplastic syndromes. $N$ Engl J Med 361(19): $1872-1885$

Tien HF, Wang CH, Lin MT, Lee FY, Liu MC, Chuang SM, Chen YC, Shen MC, Lin KH, Lin DT (1995) Correlation of cytogenetic results with immunophenotype, genotype, clinical features, and ras mutation in acute myeloid leukemia. A study of 235 Chinese patients in Taiwan. Cancer Genet Cytogenet 84(1): 60-68

Toi M, Hoshina S, Takayanagi T, Tominaga T (1994) Association of vascular endothelial growth factor expression with tumor angiogenesis and with early relapse in primary breast cancer. Jpn J Cancer Res 85(10): 1045 - 1049

Verstovsek S, Estey E, Manshouri T, Giles FJ, Cortes J, Beran M, Rogers A, Keating M, Kantarjian H, Albitar M (2002) Clinical relevance of vascular endothelial growth factor receptors 1 and 2 in acute myeloid leukaemia and myelodysplastic syndrome. Br J Haematol 118(1): $151-156$

Watarai M, Miwa H, Shikami M, Sugamura K, Wakabayashi M, Satoh A Tsuboi K, Imamura A, Mihara H, Katoh Y, Kita K, Nitta M (2002) Expression of endothelial cell-associated molecules in AML cells. Leukemia 16(1): 112-119

This work is published under the standard license to publish agreement. After 12 months the work will become freely available and the license terms will switch to a Creative Commons Attribution-NonCommercial-Share Alike 3.0 Unported License. 